\title{
ANÁLISE FINANCEIRA DE UMA PROPRIEDADE RURAL COM PRODUÇÃO DE BOVINOS DE CORTE
}

\author{
Natália Rodrigues dos Santos ${ }^{1}$ \\ Lucas Silva Leitzke ${ }^{2}$ \\ Victória Severo Navarro 3 \\ Oscar Rodrigo Moreles Rodrigues ${ }^{4}$ \\ Marcia Goulart Lopes Coradini ${ }^{5}$ \\ Andressa Dutra Piovesan Rossato 6 \\ Michele da Rosa Scholant Simões ${ }^{7}$ \\ Eloisa Bianchi ${ }^{8}$
}

RESUMO: O agronegócio brasileiro encontra-se em constante expansão, frente a esta situação os produtores vincularam a gestão do manejo dos animais com a contabilidade rural para que assim consiga evoluir no mercado pecuário e alcance maior rentabilidade. Baseado nestes dados este levantamento teórico prático tem por objetivo analisar a eficiência econômica financeira de um rebanho de bovino de corte em uma propriedade rural de $\mathrm{x}$ hectares. Primeiramente foi realizado um encontro com o responsável pela fazenda, no qual aferiu-se o número de animais entre bovinos e equinos que trabalham no sistema $\mathrm{x}$ (750 bovinos e is equinos), os dados referentes ao manejo e a sanidade dos animais por categorias, assim como informações referentes ao controle do gerenciamento administrativo. Logo após foi executado a verificação do inventário da propriedade onde analisou-se o patrimônio, os custos e despesas, a receita, a lucratividade, o fluxo de caixa e a depreciação no ciclo produtivo. Concluímos ser de extrema importância a associação e o gerenciamento dos índices zootécnicos, manejo geral e reprodutivo, com a contabilidade patrimonial, considerando que estes possibilitam ao produtor, aumentar sua eficiência produtiva e por consequência elevar o seu capital. Ressalta-se que a execução do balanço anual da propriedade é extremamente significativa para que o produtor rural consiga estruturar os investimentos e modernização implementados na propriedade.

Palavras-chave: Agronegócio. Bovinocultura. Administração.

\footnotetext{
${ }^{\mathrm{I}}$ Discentes do Curso Medicina Veterinária, Nível VIII 2021/2 - Faculdade IDEAU de Bagé - Bagé/RS.

${ }^{2}$ Discentes do Curso Medicina Veterinária, Nível VIII 202I/2 - Faculdade IDEAU de Bagé - Bagé/RS.

${ }^{3}$ Discentes do Curso Medicina Veterinária, Nível VIII 2021/2 - Faculdade IDEAU de Bagé - Bagé/RS.

${ }^{4}$ Discentes do Curso Medicina Veterinária, Nível VIII 2021/2 - Faculdade IDEAU de Bagé - Bagé/RS.

${ }_{5}^{5}$ Docentes do Curso Medicina Veterinária, Nível VIII 2021/2 - Faculdade IDEAU de Bagé - Bagé/RS.

${ }^{6}$ Docentes do Curso Medicina Veterinária, Nível VIII 2021/2 - Faculdade IDEAU de Bagé - Bagé/RS.

${ }^{7}$ Médica Veterinária - Professora Centro Universitário Ideau Bagé. Mestre em Melhoramento Animal. Doutoranda em Melhoramento Animal.

${ }^{8}$ Docentes do Curso Medicina Veterinária, Nível VIII 2021/2 - Faculdade IDEAU de Bagé - Bagé/RS.
} 
ABSTRACT: The Brazilian agribusiness is in constant expansion, facing this situation the producers linked the management of animal management with rural accounting so that it can evolve in the livestock market and achieve greater profitability. Based on this, this theoretical and practical survey aims to analyze the financial economic efficiency of a beef cattle herd on a rural property. First, a meeting was held with the person in charge of the farm, in which the number of animals (750 cattle and is horses) was measured, data referring to the handling and health of the animals by category, as well as information regarding the control of administrative management. Soon after, the property's inventory was verified, where the assets, costs and expenses, revenue, profitability, cash flow and depreciation in the production cycle were analyzed. We conclude that the association and management of zootechnical indices, general and reproductive management, with patrimonial accounting is extremely important, considering that these enable the producer to increase his productive efficiency and, consequently, raise his capital. It is noteworthy that the execution of the property's annual balance is extremely significant for the rural producer to be able to structure the investments and modernizations implemented in the property.

Keywords: Agribusiness. Beef Farming. Administration.

\section{INTRODUÇÃO}

Nos últimos anos o agronegócio apresentou um crescimento exponencial no Brasil, o que gerou uma concorrência entre empresários rurais. Com a finalidade de obter melhores resultados os produtores associaram a contabilidade rural à gestão de bovinos, para que o pecuarista consiga dar passos longos no seu negócio e sobreviva no mercado que está em constante mudança.

Para realizar a contabilidade em um sistema de produção devemos considerar os aspectos sociais, econômicos e as tomadas de decisões impostas pela propriedade para trazer benefícios na produção. O gerenciamento das saídas e entradas permite que os empresários rurais percebam quais são os maiores custos e despesas que mais impactam na sua atividade, este deve ser associado a realização da apuração da rentabilidade, do patrimônio total e da lucratividade obtida pelo negócio em um determinado período.

Deste modo para a implementação da administração rural do gado de corte, é preciso conhecer todos os pontos da propriedade como: o planejamento, os números de animais, o investimento em tecnologias aliadas a produção, a raça, o potencial genético do gado, as medidas de controle sanitário, o acompanhamento nutricional, mão de obra e a obtenção de equipamentos que promovam o bem-estar dos animais.

Considerando a importância da bovinocultura de corte, e o acompanhamento financeiro e produtivo no Brasil, este projeto tem como objetivo analisar a gestão e 
administração de uma propriedade rural, verificando a eficiência econômica/financeira do rebanho bovino de corte produzido.

\section{DESENVOLVIMENTO}

Nesta parte do trabalho será detalhado o referencial teórico, a metodologia empregada e os resultados encontrados. Contém a exposição ordenada e pormenorizada do assunto tratado do estudo.

\section{I Referencial teórico}

\section{I.I Sistema de criação pecuária de corte}

A produção na pecuária de corte se fraciona-se em três ciclos: cria (produção de bezerros), recria (preparamento de animais para reprodução ou engorda) e terminação (engorda e encerramento para o abate), que formam um ciclo produtivo e encontram-se inter-relacionadas (OAIGEN, 2007).

\subsubsection{Bovinocultura de corte no Brasil}

De acordo com Euclides Filho (2007), nos últimos anos, a produção de gado de corte no Brasil se exaltou como um dos mais significativos produtores de alimentos e se introduziu no mercado internacional. Entretanto, apesar da posição próspera no comércio exterior, evidenciada por exportações maiores a 2.00o.ooo de toneladas, os avanços esperados nas margens econômicas do segmento dentro da porteira não foram assegurados (BARCELLOS et. al., 2005).

Para Lopes et al. (2015), no desenrolamento das tarefas no campo, o clima é um elemento que implica de modo direto na criação de gado e afeta os preços dos animais. Levando em consideração que durante o ano, em determinadas estações, as pastagens estão adequadas para produção de bovinos, deste modo, quando as situações climáticas estão favoráveis, há uma variação no peso do gado, visto que os animais gordos podem ser comercializados para auferir bons rendimentos (GALVÃO et al., 2020).

Segundo Gomes et al. (2020) posteriormente à análise de informações é possível concluir que o Brasil será um dos maiores recarregados pelo provimento de carne bovina para o comércio mundial nos próximos anos. De acordo com Lopes et al. (2015), para que o pecuarista tenha uma lucratividade satisfatória, é crucial o uso da economia de 
escala, que está diretamente relacionada com o aumento da quantidade produzida e a manutenção dos mesmos custos fixos de produção.

\title{
2.1.3 O agronegócio e o mercado financeiro brasileiro
}

O agronegócio brasileiro é incumbido por uma parte importante do Produto Interno Bruto (PIB), e a bovinocultura de corte tem grande representatividade na produção (GOMES et. al., 2020). E tem considerável colocação na economia brasileira, principalmente após o início da crise financeira do país em meados de 2014, e representou cerca de 22\% do PIB em 2017 (ABIEC, 2018).

\begin{abstract}
Segundo dados do Centro de Estudos Avançados em Economia Aplicada (CEPEA/USP, 2020) em parceria com a Confederação da Agricultura e Pecuária do Brasil (CNA), o PIB do Brasil em 2019 foi de $R \$ 7,4$ trilhões, sendo que deste total $2 \mathrm{I}, 4 \%$ foi oriundo do agronegócio; dessa parcela, 32\% correspondente a $\mathrm{R} \$$ 494,8 bilhões é referente a atividade pecuária, que tem uma importância grandiosa para a economia, sendo o Brasil o maior exportador de carne bovina e o segundo maior produtor do mundo, ficando atrás somente dos EUA (CNA, 2020).
\end{abstract}

No entanto o setor é altamente vulnerável às imprecisões da mercancia, dado que o produtor não interfere no preço de venda, restando como forma de maximizar os ganhos a eficiência produtiva, o que indica a inevitabilidade do planejamento produtivo e o emprego de técnicas pertinentes de exploração (FERREIRA,2019). Na atualidade, o Brasil gera ıo milhões de toneladas de carne bovina e deste, $20,8 \%$ são transacionados para outros países (ABIEC, 2020).

\subsubsection{Contabilidade}

Segundo Vaqueiro et. al (2005) contabilidade é uma área que examina, lavra e delimita o patrimônio, em resultância dos atos e fatos administrativos estabelecidos por seus gestores, expondo ao final de um determinado período o produto econômicofinanceiro obtido.

De acordo com Crepaldi (1998), a contabilidade rural é uma ferramenta administrativa, que gere o patrimônio e mensura os ganhos das entidades rurais, apresentando aos usuários as respectivas avaliações. Já a contabilidade da Pecuária conforme Santos et al. (2002), "é a arte de criar e tratar o gado". Define-se o gado como sendo um "conjunto de animais (carneiro, cavalos, bois, cabritos, etc.) criados para variados objetivos" (HOUAISS, 2004). 


\subsubsection{Administração rural e controle econômico-financeiro do agronegócio}

Um desafio a ser superado por empresas rurais, sobretudo, as empresas familiares, é saber mensurar os custos e alocá-los conforme as particularidades e o ciclo de vida, aderindo uma base de cálculo para que a verificação dos custos possa originar uma análise econômico-financeira que corrobora a realidade da empresa, onde o proprietário seja capaz de estimar e compreender qual atividade é a mais rentável (BARBOSA et. al., 2012).

Portanto, os componentes técnicos aplicados à produção são muito importantes, mas somente quando a gestão do processo produtivo for eficaz, a melhoria da eficiência será convertida em benefícios financeiros (CÉZAR et al., 2004).

Os índices de pecuária são dados produtivos, quantitativos e qualitativos, envolvendo todas as partes do desenvolvimento animal, eles refletem o desempenho de vários parâmetros do desenvolvimento da pecuária em formato digital (a relação entre os dados) (PEREIRA, 2002). Conforme Garcia et. al. (2020), de modo geral, os índices zootécnicos mais empregues na atividade de cria de gado de corte são: a taxa de prenhez, taxa de natalidade, taxa de desmama, taxa de mortalidade.

\subsubsection{Patrimônio}

O termo patrimônio corresponde ao conjunto de bens pertencentes a um indivíduo ou a uma empresa; o constitui-se de uma fração com valores positivos: Ativo, e de uma parte com valores negativos: Passivos (MIRANDA, 2002).

Ainda segundo Miranda (2002), o ativo é constituído pelos bens e direitos, e o passivo pelas obrigações; o excedente do ativo sobre o passivo é o capital, conhecido como patrimônio líquido que aparece no passivo, para completar a igualdade entre o total do ativo e do passivo, resultando na equação patrimonial.

\subsubsection{Custo e Despesa}

Segundo Padoveze (2006), custo pode ser estabelecido como a aferição econômica dos recursos (produtos, serviços e direitos) angariados para a obtenção e a venda de mercadorias e serviços empresáriall (a quantia paga por ele, nada mais é que o custo).

As Despesas são os gastos realizados para vender e enviar os produtos, e estão ligados à administração ou vendas (PADOVEZE, 2006). Considera-se os impostos sobre a venda como despesas, assim como os demais tributos pagos pela propriedade, além dos 
gastos com funcionários não envolvidos

na produção dos bovinos, tais como contador, secretária e outros (MELZ, 2009).

\subsubsection{Receita}

De acordo com Velosso (2016), a receita bruta (ou o faturamento, no período anterior) engloba o total do valor obtido com a venda de mercadorias e a prestação de serviços ou o valor remanescente. Christofari et al. (2010), destacam que no meio agropecuário, as receitas são obtidas em alguns períodos no decorrer do ano, e geralmente, as despesas disseminam-se ao longo do ano, isto porque a grande parte da receita surge com a venda dos produtos e sofre influência da quantidade disponível para comercialização.

\subsubsection{Lucro Líquido}

O lucro é auferido pela diferença entre a receita (preço estipulado) menos os custos e despesas incorridas na produção (GARCIA et. al 2020). De acordo com Lopes et al. (2015), para que o produtor tenha uma satisfatória lucratividade, é fundamental a aplicação da economia de escala, que está ininterruptamente correlacionada com a amplificação da quantidade produzida e a manutenção dos mesmos custos fixos de produção.

A conquista da lucratividade é efeito de ações como conhecimento da atividade / negócio, planejamento de vendas, habilidades de negociações e controle de custos (CRUZ et. al 2019).

\subsubsection{Fluxo de caixa}

O fluxo de caixa é o controle das entradas (receitas) e saídas (despesas) envolvidas no sistema de produção, possibilitando a obtenção do fluxo líquido mensal (Peres, 2006).

Sendo admitido como entradas as receitas advindas da venda de animais durante o período avaliado e o saldo do inventário de bens imobilizados ao final deste; como saídas, os investimentos em benfeitorias (animais, terra, equipamentos) no início do período, e as despesas ocorridas em todo o processo produtivo, como a compra de insumos, manutenção de benfeitorias, cercas, máquinas e pastagens, os gastos com alimentação, o pagamento da mão-de-obra, ferramentas e utensílios, combustível, assistência técnica, medicamentos, associação de criadores, taxas e impostos (FERREIRA 2019). 


\section{I.II Depreciação}

A depreciação simboliza a redução de valor resultante no uso de um bem durante a sua vida útil, não tendo esse, um crescimento de seu valor com o tempo (SALAZAR et. al 2004). Destaca-se que a depreciação recai sobre os bens que têm vida útil finita, portanto, a terra não se identifica custos de depreciação (BARBOSA et. al 2012).

Entretanto, Santos et. al (2009) apontam que a legislação fiscal não estabelece taxas de depreciação para bens rurais, tornando livre a delimitação das efetivas premissas de depreciação de seus bens, contando que perfaz a prova da vida útil por intermédio de um laudo técnico formulado por um profissional da área agropecuária.

\subsection{Material e Métodos}

Primordialmente foi realizado um levantamento teórico a fim de compreender como implementar e analisar o gerenciamento de um estabelecimento rural, sendo escolhido uma propriedade localizada no 2o Distrito de Dom Pedrito, destinada a pecuária, onde 750 animais são bovinos (Figura I) dispersos nas três etapas de produção (cria, recria e terminação) e is equinos (Figura 2) utilizados para o trabalho diário na propriedade.

Como técnica de pesquisa foi feita a aplicação de entrevista, por meio de um formulário (anexo 3) estruturado com perguntas para o responsável gerencial da propriedade.

Figura I- Bovinos da propriedade.

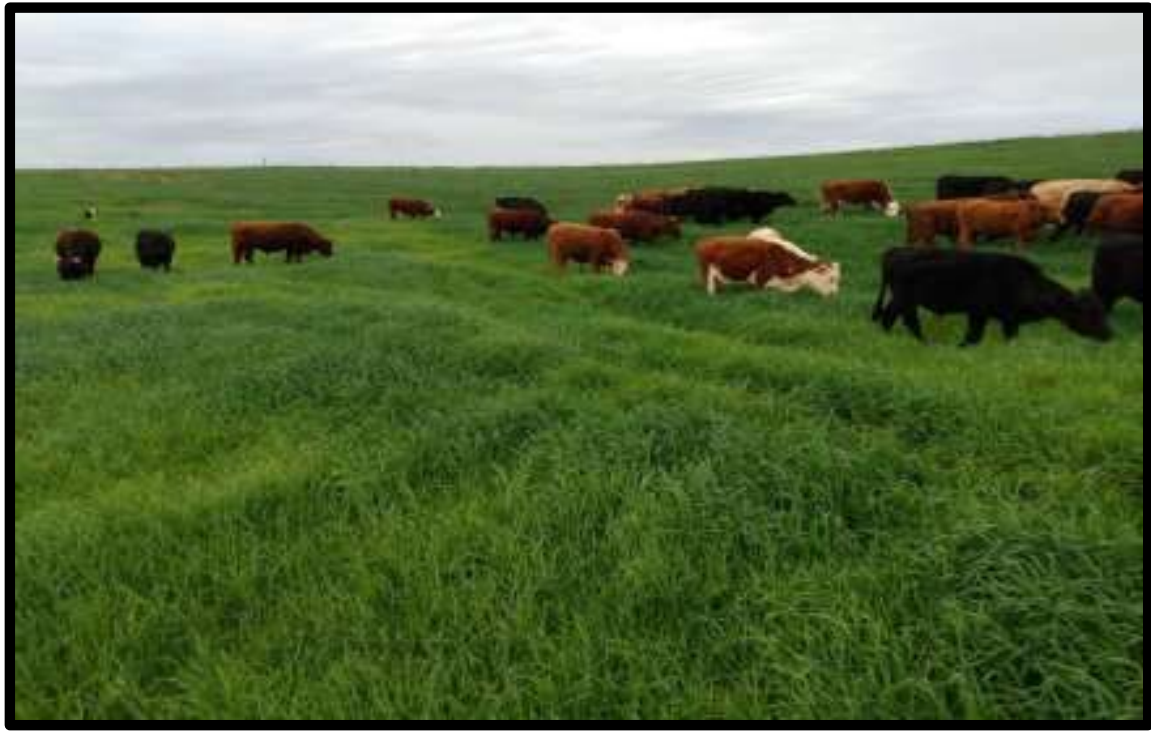

Foto: NAVARRO, V.S., 2021, Dom Pedrito/RS. 
Figura 2- Cavalos da propriedade.

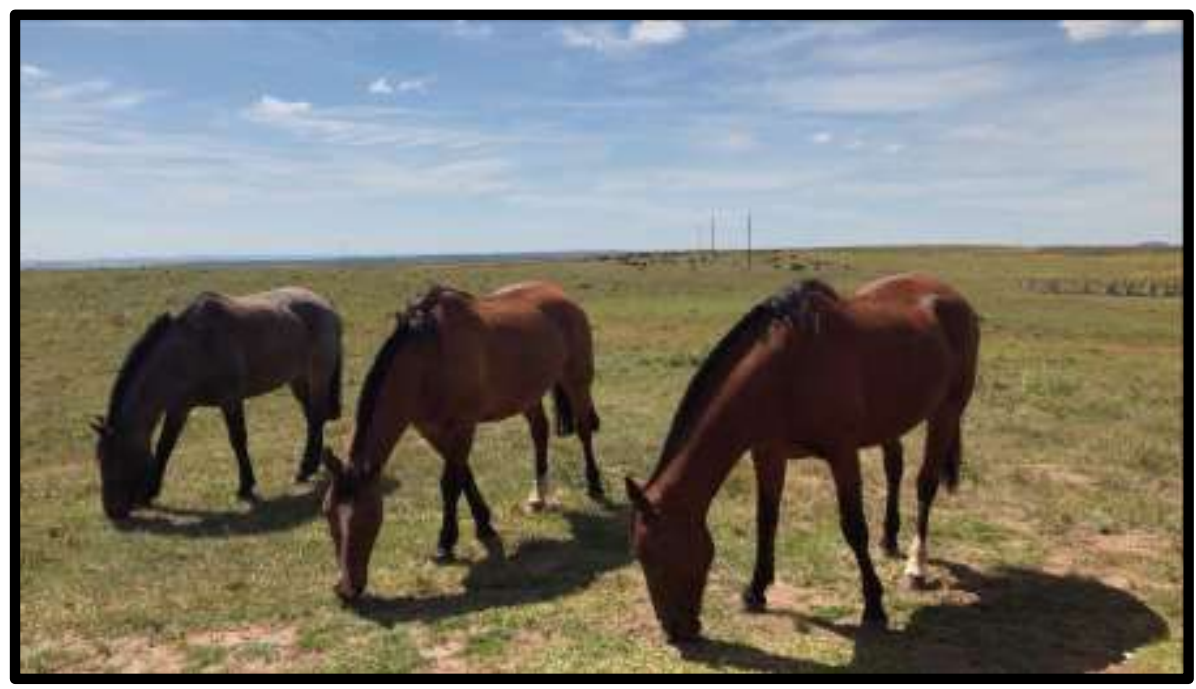

Foto: NAVARRO, V.S., 2021, Dom Pedrito/RS.

\subsection{Dados da propriedade}

O proprietário é o administrador da fazenda e atua há cerca de 38 anos na bovinocultura de corte, onde esta é a sua única fonte de renda familiar, sendo os principais objetivos da propriedade: produzir animais gordos para o abate, venda de novilhas e terneiros para a feira regional.

A propriedade possui uma área total de 800 hectares (ha), que se divide em 300 ha de campo próprio (Figura 3 ) e 500 ha de arrendamento de campos lindeiros, com um gasto de $4.00 o k g$ de boi/quadra/ano. No que se refere a área total da propriedade, 200 ha são de pastagens cultivadas de inverno: aveia e azevém, onde é realizado adubação com N-P-K; o restante das 6ooha são de campo nativo melhorado com azevém, o qual é manejado nos meses de junho/julho com queimadas estratégicas para a rebrota para o controle de plantas invasoras.

A área é dividida em potreiros, que são pastejados por lotes de animais conforme a necessidade nutricional e disponibilidade forrageira onde: os destinados a produção do ano seguinte ficam em campo nativo e os que serão comercializados são colocados na pastagem de inverno para ganho de peso, por um período médio de 120 dias.

Para a obtenção de resultados o gestor desta propriedade faz a associação de técnicas de manejo (geral e reprodutivo) juntamente com avaliação de alguns índices zootécnicos, objetivando maior produtividade. 
Figura 3 - Vista panorâmica da propriedade.

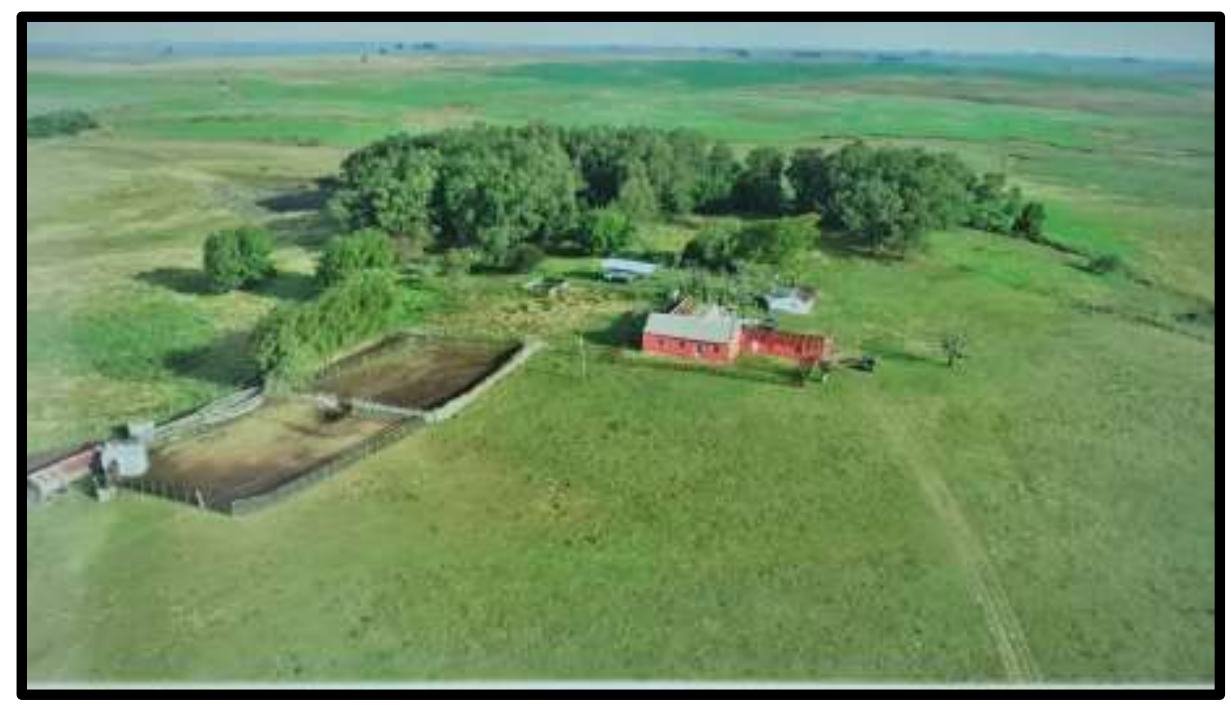

Foto: NAVARRO, V.S., 2021, Dom Pedrito/RS.

\subsubsection{Manejo geral e reprodutivo}

Em relação ao manejo geral, os animais são divididos em categorias (descritas a seguir), todas estas suplementadas com sal comum, durante todo período que os animais estão na propriedade; incluindo uma suplementação com RoboForte para as vacas gestantes.

- Manejo de touros: $O$ critério de escolha dos touros é baseado no fenótipo e a diferença esperada na média das progênies (DEP) do animal; as raças utilizadas são adquiridas através de leilões, tendo predileção por Braford e Angus. Para o manejo reprodutivo nesta categoria é realizado avaliação de dentição e exame andrológico pré-monta.

- Manejo das Matrizes: Não há critério de triagem racial destas, sendo usado como método de seleção a avaliação da dentição e diagnóstico de gestação, onde o sistema de acasalamento é somente monta natural.

- Manejo das novilhas: A idade do primeiro acasalamento é aos 24 meses, sendo este o principal critério de eleição; as novilhas que ficam na propriedade são todas de produção própria.

- Manejo de terneiros: Estes animais são marcados, assinalados e pesados após o nascimento; sendo realizado o desmame aos 9 meses de idade. 


\subsubsection{Sanidade e índices de Pecuária}

Para avaliação dos parâmetros de desenvolvimento da propriedade, o proprietário relata utilizar como método de controle: taxa de prenhez, taxa de desmame e peso médio dos animais para descarte. Ainda de acordo com o mesmo, a propriedade possui uma lotação animal de I,07 UA/h a e uma relação de I touro para 26 vacas.

No decorrer da permanência desses animais na propriedade, como métodos sanitários são realizadas imunizações para: leptospirose, IBR, BVD, brucelose, carbúnculo sintomático e hemático; no que se refere a vacina da febre aftosa, esta não é realizada por ser erradicada no Rio Grande do Sul no ano de 2020, e a vacinação para tristeza parasitária bovina (TPB) não é feita devido ao valor elevado relativo à quantidade de animais.

A vermifugação é realizada em duas etapas: animais jovens (cinco vezes/ano) e adultos (duas vezes/ano); sendo distribuídos nas categorias os seguintes princípios ativos: Levamisole, Moxidectina, Benximidazol, Doramectina e Albendazol. Com referência aos ectoparasitas, o controle é realizado por banho de imersão com Colosso FC30 (seis vezes/ano) e a utilização do produto Acatak Pour On, uma vez ao ano.

\subsubsection{Avaliação Econômica da propriedade}

Primeiramente foi realizado o inventário de animais e bens, seguido da saúde econômica da propriedade no período de junho de 2020 até junho de 202I, sendo analisados os seguintes itens: patrimônio, custo e despesa, receita, lucratividade, fluxo de caixa e depreciação.

\subsubsection{Inventário de animais e bens}

O inventário de animais e bens (Anexo 2 - Tabela 7). que foi obtido através da entrevista e descrito no item 2.2 deste levantamento sendo ainda coletado ainda dados econômicos referentes a estes, utilizando como principal dispositivo o questionário disposto em anexo 3.

\subsubsection{Receita}

Com o intuito de alcançar a receita bruta (faturamento de venda e prestação de serviços) aplicou-se a seguinte fórmula:

$$
\text { Receita }=\text { Numero de animais vendidos } \times(\text { média de } \mathrm{kg} \times \text { Valor do } \mathrm{kg})
$$




\subsubsection{Patrimônio Bruto}

Para a obtenção do patrimônio bruto foi realizado a soma de todos os bens da propriedade.

$$
P B=M+I+B f+T+R
$$

Onde: PB - Patrimônio Bruto, , M - Máquinas, , I - Implemento

$\mathrm{B}_{\mathrm{f}}-$ Benfeitorias

$\mathrm{T}-\mathrm{Terra}$

$\mathrm{R}$ - Receita

\subsubsection{Custo e Despesa}

Tendo em conta os custos e despesas obtidos através do questionário, confeccionouse uma equação contendo: mão-de-obra, sanidade e plantio de pastagem.

Sendo o custo calculado através da seguinte equação:

$$
C t=M o+S+P
$$

Onde: Ct - Custo Total, Mo - Mão-de-obra, S - Sanidade

P - Plantio

Já o valor de despesas, foi alcançado por meio do método a seguir onde, classifica-se como gastos gerais, todo gasto não relacionado a produção.

$$
\text { Despesas }=\text { soma dos gastos gerais }
$$

\subsubsection{Lucro liquido}

Para essa categoria primeiramente foi identificado a receita total do sistema e subtraiu-se os custos e despesas com a atividade.

$$
L=R-(C+D)
$$

Onde: L - Lucro líquido

$\mathrm{R}$ - Receita

C - Custos

D - Despesas 


\subsubsection{Fluxo de caixa}

Considerando o valor de entrada obtida através de animais durante o período da venda subtraiu-se as despesas: combustível e despesas em geral.

$$
F C=R-D
$$

Onde: Fc - Fluxo de caixa

R - Receita

D - Despesa

\subsubsection{Depreciação}

Observando que um produto após sua compra e uso sofre algum tipo de depreciação ao longo da sua vida útil, utilizou - se a seguinte fórmula:

$$
D p=\frac{P i-P f}{T u}
$$

Onde: $\mathrm{Pi}$ - é o preço pago pelo produto;

Pf - Valor residual do produto

Tu - tempo de uso

\subsection{Resultados e Discussão}

A partir da entrevista realizada foi possível obter os seguintes resultados:

\subsection{Avaliação gerencial do rebanho}

Observa-se que de modo geral o manejo com os animais encontra-se de maneira correta, porém destaca-se assim como GARCIA et. al (2020), a importância do uso dos índices sanitário para que haja um melhor controle da propriedade. Quanto a isso verificase que nesta chácara há uma falta de monitoramento de dados quanto: a taxa de mortalidade e natalidade dos animais, sendo estes dados importantes para a medição qualitativa e quantitativa econômica para a fazenda. Percebe-se ainda que não é realizada a vacinação para $\mathrm{TPB}$, podendo este fato trazer prejuízo sanitário e econômico, caso ocorra um episódio de contaminação por este parasita nesta propriedade.

Nota-se que esta fazenda já dispõe de um controle patrimonial e financeiro, pré estruturado, necessitando somente a aplicação dos métodos gestoriais anuais (avaliados a 
seguir), para a verificação dos ativos e passivos da propriedade, sendo a importância do controle destes explícita por BARBOSA et. al (2012).

\subsubsection{Semovente}

Neste item foi confeccionado o inventário de animais juntamente com o seu valor de venda (Tabela I), a fim de compreender o processo produtivo da propriedade rural, onde observa-se que nesta fazenda, há uma predominância de bovinos, dispondo de is equinos que são utilizados para o trabalho no dia-a-dia, obtendo-se assim um Semovente (junho 2020 até junho 202I) de R\$2.548.238,oo.

\section{Tabela I - Semovente}

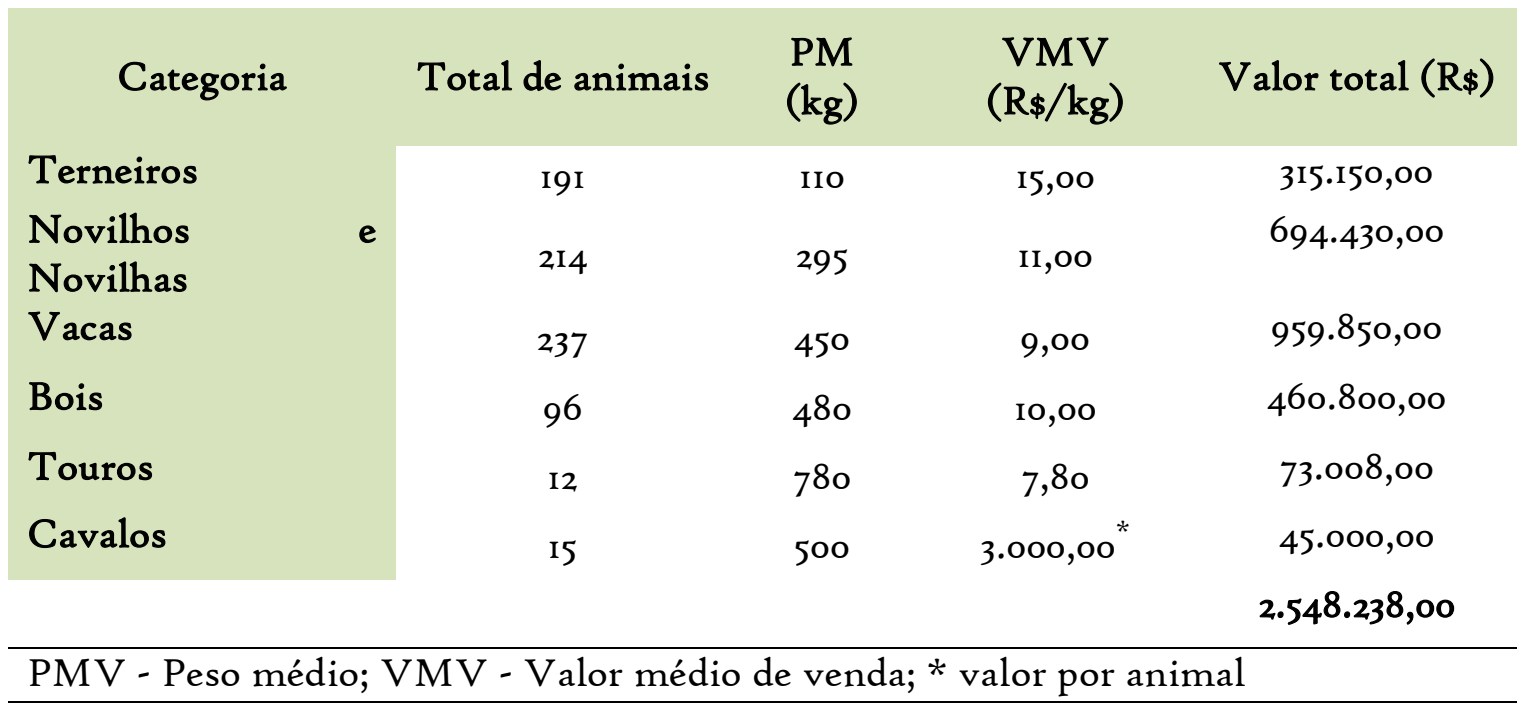

\subsubsection{Custo e despesas}

Para a análise dos custos foi utilizado o esquema descrito no tópico (2.2.5.4) deste levantamento e exposto na tabela (Tabela 2). Podendo observar um valor líquido de custos e despesas respectivamente de: $\mathrm{R} \$ \mathbf{1 2 0 . 6 6 0 , 0 0}$ e $\mathrm{R} \$ 11 \mathrm{I} .000,00$, considerando assim como PADOVEZE (2006) os custos, a somatória do valor gasto para a produção e; despesas todo gasto não relacionado a produção, preceito esse de acordo com o conceito expresso por MELZ (2009). 
Tabela 2 - Valor Total de custos e despesas

\begin{tabular}{|c|c|c|c|}
\hline \multicolumn{4}{|c|}{ Tabela avaliativa de custos e despesas ${ }^{*}$} \\
\hline & Item & Valor $(\mathrm{R} \$)$ & Valor Total $(\mathrm{R} \$)$ \\
\hline \multirow{3}{*}{ Custos } & Sanidade & $30.000,00$ & \multirow{5}{*}{$120.660,00$} \\
\hline & Pastagem & $26.860,00$ & \\
\hline & Suplementação & $4.800,00$ & \\
\hline \multirow{5}{*}{ Despesas } & Mão de obra & $35.000,00$ & \\
\hline & Arrendamento & $240.000,00$ & \\
\hline & & & \multirow{3}{*}{ III.00o,00 } \\
\hline & Combustível & $14.000,00$ & \\
\hline & Despesas gerais & $97.000,00$ & \\
\hline
\end{tabular}

Montante faturado no período de junho de 2020 até junho de 202I

\subsubsection{Depreciação}

Utilizou-se a fórmula apresentada anteriormente em metodologia para a análise da depreciação do maquinário e implementos (Tabela 3), onde é possível verificar o valor anual preciso para repor as máquinas e implementos por mais modernos, sendo este valor total de $\mathrm{R} \$ 327$,00 mensais durante 120 meses ou $\mathrm{R} \$ 39.240 .00 /$ anuais durante os próximos Io anos.

Tabela 3- Depreciação de Máquinas e implementos

\begin{tabular}{|c|c|c|c|c|c|c|}
\hline \multicolumn{7}{|c|}{ Depreciação de máquinas e implementos } \\
\hline \multirow{4}{*}{ Máquinas } & Item & Valor $\mathrm{R} \$$ & $\begin{array}{c}\text { Vida } \\
\text { útil } \\
\text { (anos) }\end{array}$ & $\begin{array}{l}\text { Ano de } \\
\text { compra }\end{array}$ & $\begin{array}{l}\text { Valor } \\
\text { residual }\end{array}$ & $\begin{array}{c}\text { Depreciação } \\
\text { R/ano }\end{array}$ \\
\hline & Trator I & 230.000,00 & Io & 2020 & $23.000,00$ & $20.700,00$ \\
\hline & Trator 2 & $35.000,00$ & Io & 2011 & $3.500,00$ & $3.150,00$ \\
\hline & Caminhão & IIO.0oo,oo & Io & 2008 & II.000,00 & $9 \cdot 900,00$ \\
\hline \multirow{3}{*}{ Implementos } & Grade & $35.000,00$ & Iо & 2020 & $3.500,00$ & $3.150,00$ \\
\hline & Semeadeira & I8.000,00 & Iо & 2021 & I. 800,00 & I. 620,00 \\
\hline & Reboque & 8.0oo,oo & Iо & 2000 & 800,00 & 720,00 \\
\hline \multicolumn{2}{|c|}{ TOTAL } & $436.000,00$ & & & 43.600 & $39.240,00$ \\
\hline
\end{tabular}




\subsubsection{Receita}

Posteriormente a análise de animais vendidos no período avaliado e expresso na tabela 6 (disponível em anexo I), utilizou-se a fórmula descrita no tópico 2.2.5.4, onde obteve-se como receita bruta o montante $\mathrm{R} \$ 1.203 .568,00$, sendo este valor calculado em concordância com os preceitos mencionado por Veloso (2016) e Cristofari (2010).

Após a obtenção da receita bruta do período avaliado, pode se observar que este produtor adquire a maior parte da sua receita (Gráfico I), através da venda de bois (38\%) e vacas $(34 \%)$, podendo associar este fato com a disposição destes animais na pastagem de inverno para ganho de peso, no período médio de 120 dias antes da comercialização dos mesmos.

$$
\text { Gráfico I - Receita da venda de animais. }
$$

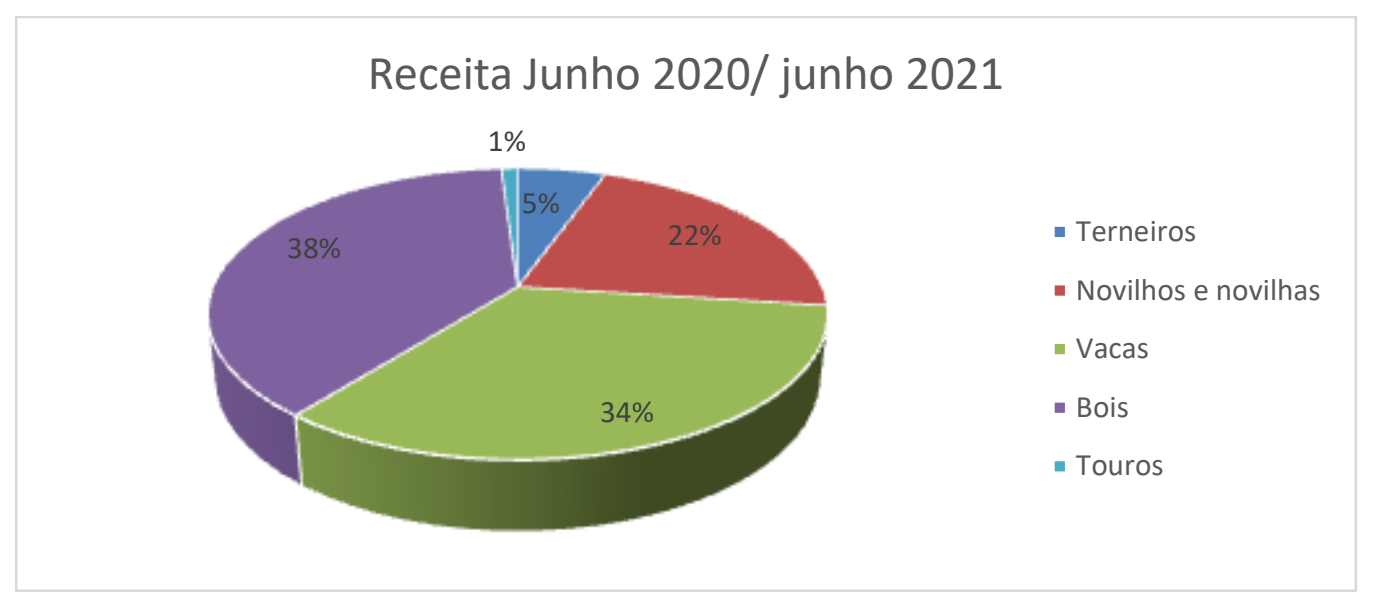

\subsubsection{Patrimônio}

Logo após a análise do total de hectares da propriedade obteve-se o valor líquido da mesma, assim como os valores referentes a benfeitorias (galpão, cerca, mangueiras e açude), máquinas (Caminhão e tratores) e implementos (grade, semeadeira e reboque). Tendo estes dados, aplicou-se a fórmula apresentada anteriormente em 2.2.5.2, estando esta de acordo com os conceitos que Miranda (2002) expressa (nos quais o patrimônio simboliza a totalidade de bens pertinentes a um estabelecimento), onde chegou- se ao patrimônio bruto (Tabela 4 ) da propriedade, que é de $\mathrm{R} \$ 8.82 \mathrm{I} .038$,oo e um patrimônio líquido de $\mathrm{R} \$ 8.589 .378$,oo. Sendo este valor líquido obtido através da subtração do patrimônio bruto das despesas/custos (somatório). 
Tabela 4 - Avaliação Patrimonial (junho 2020/ junho 202I).

\begin{tabular}{|c|c|c|c|}
\hline Categoria & Valor $(\mathrm{R} \$)$ & $\begin{array}{c}\text { Patrimônio } \\
\text { bruto(R\$) }\end{array}$ & $\begin{array}{c}\text { Patrimônio líquido } \\
\left(\mathrm{R}_{\$}\right)\end{array}$ \\
\hline Máquinas & $375.000,00$ & & \\
\hline Implementos & 61.00o,oo & & \\
\hline Benfeitorias & 107.000,00 & & \\
\hline Terra ${ }^{\mathrm{I}}$ & $5.600 .000,00$ & 8.821.038,00 & $8.589 .378,00$ \\
\hline Receita & $\mathrm{I} .203 .568,00$ & & \\
\hline Somovente ${ }^{2}$ & I. $474.470,00$ & & \\
\hline Despesas + Custos & $231.660,00$ & & \\
\hline
\end{tabular}

\subsubsection{Lucro Líquido}

O lucro (Tabela 5) da propriedade no período em questão foi de $\mathrm{R} \$ 971.908,00$ (sendo este valor estimado através da fórmula descrita anteriormente na metodologia, cujo subtítulo é "lucro líquido"). Concordando o número atingido com o conceito referido por Garcia et. al (2020), que expressa o lucro sendo a diferença entre a receita bruta e os custos/despesas com a atividade.

Tabela 5 - Valor total de lucro.

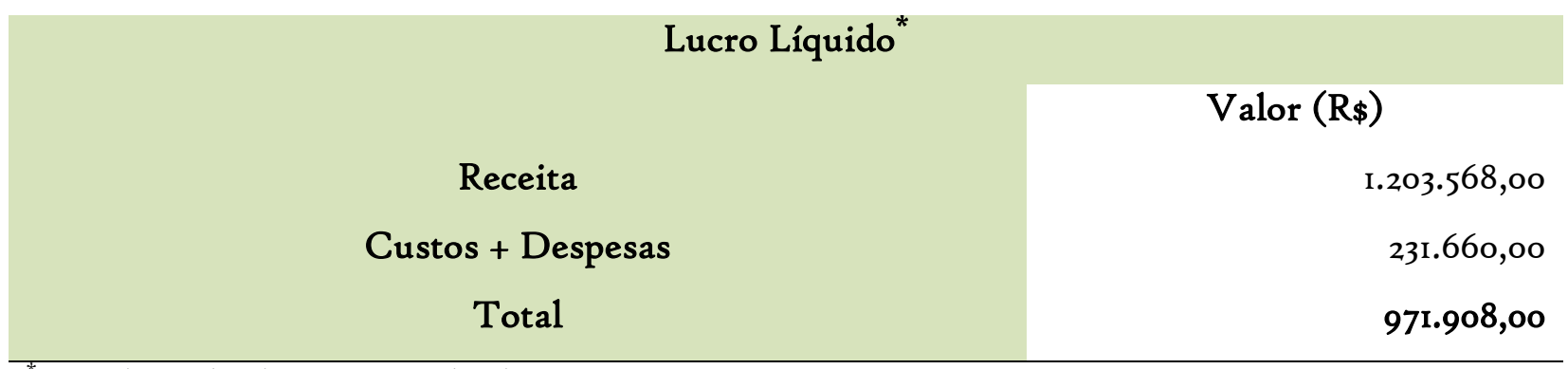

Período: junho de 2020 até junho de 2021

\subsubsection{Fluxo de caixa}

Após admitir-se os valores de receita provenientes da venda de animais durante o período avaliado e os custos ocorridos durante o processo produtivo, fez-se a subtração dos mesmos, coincidindo-se com o princípio descrito por Peres (2006) e Ferreira (2020); sendo este valor de R\$1.082.908,oo. 


\section{CONCLUSÃO}

Conclui- se neste levantamento teórico prático, ser de extrema valia a associação e gerenciamento dos índices sanitários, manejo e contabilidade patrimonial, visto que ambos proporcionam ao produtor rural, ampliar a sua produtividade e consequentemente aumentar o seu capital. Observa- se ainda que a realização do balanço anual da propriedade é de suma importância de modo que, este permite que o produtor seja capaz de coordenar quais particularidades sua propriedade carece de investimentos e quais, demanda modernização tal como o capital disponível para a realização destes.

$\mathrm{Na}$ comparação dos dados foi possível perceber que esta propriedade apresenta como cargo chefe a comercialização de bovinos, sendo sua maior parcela de rendimentos a venda de bois e vacas. Verifica- se ainda que atualmente esta produção encontra-se economicamente positiva, sendo obtido no período produtivo (junho 2020 até junho 202I), um lucro líquido de $\mathrm{R} \$ 971.908,00$. Enfatiza- se que para a continuidade da prosperidade financeira desta propriedade para os próximos anos, o produtor rural deve permanecer controlando e aprimorando a pastagem e a sanidade dos animais para que mantenha assim, o equilíbrio do seu patrimônio.

Com relação aos maquinários e implementos, observa- se que a avaliação destes pela depreciação é de grande valia, permitindo ao gestor da propriedade programar a substituição destes sem que haja um déficit financeiro. Observa- se que o objetivo deste levantamento foi atingido, visto que foi possível aos autores deste conhecer e identificar os fatores importantes para a gestão de uma propriedade rural.

\section{REFERÊNCIAS}

ABIEC - associação brasileira das indústrias exportadoras de carnes. Perfil da pecuária no Brasil - Relatório anual 2018. Disponível em: 〈http://abiec.siteoficial.ws/images/upload/sumario-pt-oro217.pdf $\rangle$. Acesso em I4/08/202I.

ABIEC - associação Brasileira das Indústrias Exportadoras de Carnes. Exportações Brasileiras de Carne Bovina, 2020. Disponível em: $\langle$ http://abiec.com.br/?s=exporta\%C3\%A 7\%C3\%B5es >. Acesso em I2/o8/2021. 
BARBOSA, L.P.; BRAGA, A.; DE SOUZA, M.A.; BRAGA, D.P.G. Contabilidade, gestão de custos e resultados no agronegócio: Um estudo de caso no Rio Grande do Sul. XIX Congresso Brasileiro de Custos - Bento Gonçalves, RS, Brasil, 2012.

BARCELlOS, J. O. J., SUÑÉ, Y. B. P., CHRISTOFARI, L. F., SEMMELMANN, C. E. N., \& BRANDÃO, F. A pecuária de corte no Brasil: uma abordagem sistêmica da produção a diferenciação de produtos. Jornadas de Economia Regional Comparada, 2, 2005.

CÉZAR, I.M.; COSTA, F.P.; PEREIRA, M.A. Perspectivas de gestão em sistemas de produção animal: desafios a vencer diante dos novos paradigmas. In: Reunião anual da Sociedade Brasileira de Zootecnia, 4I., 2004, Campo Grande. Anais... Campo Grande: SBZ, 2004 .

CHRISTOFARI, L. F., BARCELlOS, J. O. J., BRACCINI NETO, J., OAIGEN, R. P., SANTOS, A. P. D., \& CANOZZI, M. E. A. Efeitos do peso vivo sobre a comercialização de bezerros de corte em leilões. Arquivo Brasileiro de Medicina Veterinária e Zootecnia, v. 62, n. 2, p. 419-428, 2010.

CNA - confederação da agricultura e pecuária do brasil. Panorama do Agro. 2020. Disponível em: < https://www.cnabrasil.org.br/cna/panorama-do-agro>. Acesso em: II/o8/202I.

CPEA. Centro de Estudos Avançados em economia aplicada. PIB do Agronegócio. CEPEA-USP/CNA/ESALQ. 2020. Disponível em: < https://www.cepea.esalq.usp.br/br/pib-do-agronegocio-brasileiro.aspx >. Acesso em: I2/08/2I.

CREPALDI, S.A. Contabilidade Rural. 2. ed. São Paulo: Atlas, 1998.

CRUZ, A. M.; GUZATTI, N. C. Custos e lucratividade na produção de bovinos no sistema de pecuária extensiva, no município de Denise - MT. Revista UNEMAT de Contabilidade, v.8, n.I6, 2019. 
DA CUNHA, J. A.; SANTOS, V.C.P.; FRANCO, M.C. O papel das cooperativas de reciclagem no gerenciamento de resíduos sólidos urbanos na região metropolitana de Belém, 202I.

EUCLIDES FILHO, K. Bovinocultura de corte no Brasil. Revista de Política Agrícola, Brasília, v. I6, n. 4, out/dez. 2007.

FERREIRA, R. L. Avaliação Econômico-Financeira de um Sistema de Cria de Gado de Corte em Região Leiteira de Minas Gerais, 2019.

GALVÃO, B. F., DA MATA DAHER, D., TERRA, R. D. C. C., \& OLIVEIRA, D. S. Gestão de custos na bovinocultura de corte: um estudo em propriedades rurais de Rondon do Pará/PA.XVII SEGeT, 2020.

GARCIA, F. Z., DE CARVALHO, C. A. B., DE CARVAlHO PERES, A. A., DOS SANTOS, D. A., DE MENDONÇA, F. M., MALAFAIA, P., \& FERREIRA, R. L. Análise dos indicadores de desempenho econômico-financeiro de sistemas de cria de gado de corte. Arq. Bras. Med. Vet. Zootec, 69(4), 1030-1038, 2020.

GOMES, M. F., \& GASPERINI, M. M. Agronegócio, bovinocultura de corte, responsabilidade social e corrupção. Brazilian Journal of Development, 6(5), 28428-28443, 2020.

HOUAISS, A. Mini dicionário Houaiss de língua Portuguesa. $2^{\underline{a}}$ ed.2004.

LOPES, M. A., DEMEU, A. A., BARBOSA, F. A., BRONDINO, J., \& CARVALHO, F. D. M. Resultados econômicos da recria e engorda de novilhas de corte: um estudo de caso no município de Curvelo-MG, nos anos de 2008 e 2009. Archivos Latino-americanos de Producción Animal, 23(2), 81-90, 2015. 
MELZ, L. J. Custos de produção de gado bovino: um enfoque da contabilidade de custos. In Anais do Congresso Brasileiro de Custos-ABC, 2009.

MIRANDA, DANIELA. Contabilidade básica. Apostila de Contabilidade e Análise de Balanços. Instituto de Estudos Superiores da Amazônia. Manaus (AM), 2002.

OAIGEN, R.P. Utilização do método dos centros de custos na pecuária de cria. Dissertação (Mestrado em Zootecnia). Universidade Federal do Rio Grande do Sul. Porto Alegre, I02p, 2007.

PADOVEZE, C. L. Curso básico para gerencial de custos. 2. ed. São Paulo: Pioneira Thomson Learning, 2006.

PEREIRA, M. F. A Construção do processo de planejamento estratégico a partir da percepção. Tese (Doutorado em Engenharia de Produção). Universidade Federal de Santa Catarina. Florianópolis, 26 de março de 2002.

PERES, R. Análise do fluxo de caixa da Medabil Sistemas Construtivos SA. 2007.

SALAZAR, J.N.A.; DE BENEDICTO, G.C. Contabilidade financeira. Cengage Learning Editores, 2004.

SANTOS, G. J. DOS; MARION, J. C.; SEGATTI, S.. Administração de Custos na Agropecuária. 3. ed. São Paulo: Atlas, 2002.

SANTOS, G.J.DOS.; MARION, J.C.; SEGATTI, S. Administração de Custos na Pecuária. 4. Ed. São Paulo. Atlas, 2009

VAQUEIRO, V. S.; JÚNIOR, F. L. C. Gestão de custos na pecuária: princípios e métodos de custeio aplicáveis na produção de touros da raça Canchim. In: Anais do Congresso Brasileiro de Custos-ABC. 2005. 
VELLOSO, A.P. ICMS na base de cálculo dos tributos sobre a receita: premissas e corolários lógicos da tese jurídica. Revista de doutrina $\mathrm{TRF}_{4}$. Disponível em:<www. revistadoutrina. trf4. jus. br/index. htm, 2016. 